


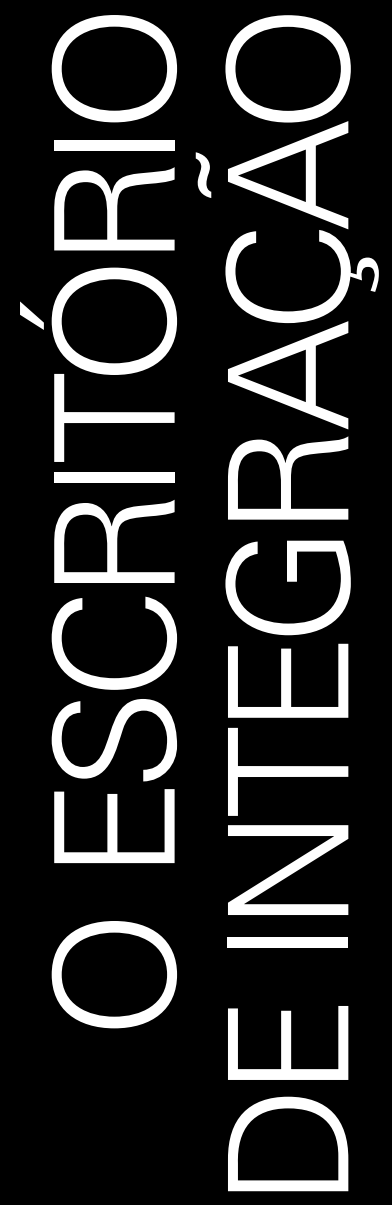





\section{O ESCRITÓRIO DE \\ INTEGRAĈ̃O DO CURSO \\ DE ARQUITETURA E \\ URBANISMO DA PUCMINAS ${ }^{1}$}

\section{INTRODUÇÃO}

O Escritório de Integração do Curso de Arquitetura e Urbanismo da PUC Minas (El), criado em 1993, é o espaço do Curso onde se canalizam e se operam as principais atividades de extensão do Curso, articulando-as com a pesquisa e o ensino.

O trabalho do El é desenvolvido por equipe de professores, estudantes estagiários e voluntários do Curso de Arquitetura e Urbanismo, e eventualmente, também de outros cursos da PUC Minas, como Direito, Engenharia Civil, Serviço Social ou Ciências Sociais.

O El tem uma sala própria, devidamente equipada, situada na entrada do prédio onde funciona o Curso de Arquitetura e Urbanismo da PUC. O El tem ainda a possibilidade de utilizar os laboratórios do Curso, como os de Informática, Maquetes e Conforto Ambiental. Em especial, o El gerencia um canteiro de obras, atrás do prédio, utilizado em aulas práticas do curso de graduação e nos Cursos de Mão de Obra Bruta que administra.

O Escritório de Integração tem como principal objetivo levar a arquitetura e o urbanismo à comunidade externa, em especial à população de baixa renda, com pouco ou nenhum acesso aos serviços de arquitetura e urbanismo. Por outro lado, busca trazer essa realidade para dentro da escola, envolvendo professores e alunos a lidar com essa realidade, e capacitando profissionais mais compromissados com a parcela da sociedade menos favorecida. Nesse processo, as atividades extensionistas são potencializadoras de reflexão e redirecionamentos das práticas de ensino e pesquisa em nosso Curso.

A atuação do Escritório de Integração é calcada nos três princípios norteadores do Projeto Político Pedagógico do Curso: inclusão, sustentabilidade e construção. A inclusão é aqui entendida como busca e experimentação de soluções para a coletivização dos direitos à habitação e à cidade, sendo seus objetivos prioritários o espaço urbano, o espaço público, os equipamentos de uso coletivo e habitação popular. No conceito de sustentabilidade, é fundamental não apenas a degradação, mas também a transformação do ambiente a partir do seu próprio potencial. Nesse sentido, busca-se incorporar às atividades desenvolvidas no nosso Curso a preocupação em formar arquitetos capazes não só de reconhecer o valor do patrimônio natural e do patrimônio construído, mas também de valorizá-los através de suas proposições. O conceito de construção é entendido sob a perspectiva de que projetar e 
planejar não se reduzem ao projeto, de uma visão ampliada da arquitetura que inclui a construção. Cabe, portanto, reconhecer que à arquitetura correspondem igualmente o saber criar e o saber fazer, a arte e a técnica. Dessa forma, incentiva-se no Curso a realização de atividades de pesquisa e de experimentação de métodos construtivos e de gestão de obras, bem como de instrumentos e mecanismos de implantação e gestão de planos urbanos.

As atividades do El têm contemplado projetos e assessoria nos âmbitos da habitação, da recuperação da capacidade instalada urbana e de áreas urbanas degradadas, do desenvolvimento de práticas habitacionais autogestionárias, e da capacitação de mão-de-obra vinculada à construção civil. O desenvolvimento dos projetos envolve atividades como desenvolvimento tecnológico da construção civil, pesquisas aplicadas, projetos arquitetônicos e complementares, acompanhamento e execução de obra, especificações e orçamentos, laudos técnicos, e cursos de formação de mão de obra.

Além dos projetos externos de extensão, o El também fomenta projetos articulados com os Laboratórios de Extensão e Pesquisa, instâncias pedagógicos optativas para disciplinas intermediárias do Curso (Ciclo Profissionalizante I). Os Laboratórios possibilitam ao corpo docente experimentar novos formatos de ensino-aprendizagem, contemplando a possibilidade de interação entre conteúdos disciplinares e projetos de extensão e pesquisa. Essas atividades aproximam os alunos da pesquisa e da prática profissional, e permitem a difusão de uma mova mentalidade de projetação entre os alunos, com maior discernimento crítico acerca dos processos e materiais construtivos, e mais sensibilidade para com as questões relacionadas à inclusão social e à sustentabilidade. Os Laboratórios se caracterizam como um diferencial dentre as práticas pedagógicas correntes nos cursos de Arquitetura e urbanismo do país, ampliando o conhecimento para além do cumprimento prioritário dos conteúdos disciplinares, e gerando um perfil diferenciado dos arquitetos urbanistas egressos da PUC Minas.

Várias das disciplinas do Curso de Arquitetura e Urbanismo já desenvolveram projetos dessa natureza, como Planejamento Ambiental Urbano, Planejamento Habitacional, Projeto de Alvenaria Estrutural e Projeto de Estruturas de Madeira e Aço.

A passagem de alunos pelo El têm influenciado vários dos Trabalhos de Graduação, com muitos dos temas de TFGs desenvolvidos a partir de trabalhos realizados no El. A temática enfatizada no El também foi determinante na criação do Curso de Especialização em Gestão Ambiental Urbana, em 2003, ministrado no IEC - Instituto de Educação Continuada da PUC Minas. Vários dos egressos da graduação fizeram o Curso de Especialização, e voltaram a trabalhar como arquitetos em projetos do El.

Dando visibilidade às atividades do El, vários dos projetos ali desenvolvidos acabam se tornando objeto de produção de artigos acadêmicos, tal como se pode demonstra nesse número dos Cadernos. 
Os projetos desenvolvidos pelo El têm origens variadas: demandas de comunidades diversas - associações comunitárias, de moradores, religiosas, pastorais de rua - que chegam via Universidade ou diretamente ao El; projetos de pesquisa ou de extensão de professores enquanto pesquisadores; projetos de pesquisa ou extensão vinculadas a disciplinas do curso. Da mesma forma, os projetos têm desdobramentos variados, operados pelas mesmas vias, e incorporando financiamentos internos ou externos: podem surgir de uma demanda externa e serem incorporados a uma atividade de ensino, pesquisa ou extensão; ou surgirem no âmbito acadêmico e serem transformados em atividades extensionistas.

\section{PROJETOS DE EXTENSÃO}

Nestes 20 anos já foram desenvolvidos mais de 110 projetos de extensão no Escritório de Integração. Mais de 200 alunos da PUC, do Curso de Arquitetura e Urbanismo e também dos cursos de Engenharia Civil, Direito, Serviço Social e Ciências Sociais participaram desses projetos. Destacaremos abaixo alguns desses projetos.

\subsection{Programa Construção e Cidadania: Cursos de formação de mão de obra para construção civil (1999-2013)}

O Programa Construção e Cidadania tem como objetivo a formação de profissionais para construção civil, por meio de cursos de formação de mão de obra. Os cursos abordam três conceitos básicos: cidadania como forma de inclusão social; construção civil como fundamento básico de uma edificação íntegra; e por último, a compreensão do meio ambiente como um sistema integrado. Como uma ferramenta de inclusão social, busca-se levar ao aluno informações muitas vezes inacessíveis, porém fundamentais para sua integração junto à sociedade. Como instrumento qualificador de mão de obra, busca-se levar os conceitos e a teoria necessários para a compreensão das implicações e os condicionantes que estão por trás de qualquer obra civil. Dessa forma, busca fazer com que o aluno compreenda a importância do conhecimento da técnica correta na construção civil, e como utilizá-la em seu benefício e em benefício da sociedade. Os cursos também contemplar informações acerca de emprego, financiamentos, regularização fundiária, mutirões no sistema de autogestão e demais assuntos de interesse ligados à construção. Desta forma, busca-se a formação de sujeitos tecnicamente capacitados, e, ainda, capazes de compreender o sistema de produção e suas contradições, bem como, os problemas ambientais a ele relacionados.

Os cursos são, também, uma oportunidade única para o aluno extensionista da PUC Minas, que tem a possibilidade de participar das atividades de um canteiro e estabelecer um contato mais próximo com a realidade social brasileira.

\section{Cursos realizados}

Os cursos tiveram início em 1999, em parceria com a ASA - Ação Social Arquidiocesana. A partir de então, foram desen- 
volvidos diversas edições do curso, cada edição com uma instituição parceira diferente, como a Ação Social Arquidiocesana, a Secretaria de Segurança Pública, e a Providencia Nossa Senhora da Conceição.

Entre 2006 e 2009, foram ministradas edições do Curso Oficial de obra Bruta em Alvenaria Estrutural, em parceria com a Secretaria de Estado de Defesa Social, como parte do Programa Fica Vivo, formando cerca de 20 oficiais de obra bruta, selecionados junto aos egressos do sistema prisional da Região Metropolitana de Belo Horizonte.

Em 2008, o Curso de Qualificação Profissional de Mão de Obra Módulo I: Fundamentos da construção se estruturou como uma prestação de serviço, sendo destinado à qualificação e formação de 20 funcionários da Empresa MRV Engenharia e Participações S.A. A execução foi realizada por profissionais da construção civil e pelo pessoal docente e técnico da PUC Minas.

Em 2011, o Curso de Qualificação Profissional de Mão de Obra Módulo I - Fundamentos da construção: Alvenaria estrutural, com 30 alunos, teve parceria com a Misereor, PBH/ Urbel, Vicariato Episcopal, PROEX e EI PUC Minas.

Em 2012, o mesmo curso teve como público alvo a população de baixa renda de Justinópolis e região, e contou com 24 alunos, sendo 17 mulheres. Teve como parceiros a PROEX e a Providencia Nossa Senhora da Conceição (antiga ASA - Ação Social Arquidiocesana). As aulas teóricas foram realizadas na Casa de Retiro Vila Fátima e, as aulas práticas, aos sábados, no Canteiro de Obras do Curso de Arquitetura da PUC. As aulas foram conduzidas por um arquiteto egresso do Curso de Arquitetura da PUCMINAS, e as aulas práticas por uma mestra de obras egressa da primeira turma do Curso Construção e Cidadania, de 1999.2

Em 2013, com as mesmas parcerias anteriores, pretende-se repetir no primeiro semestre o curso de 2012, e no $2^{\circ}$ semestre ministrar o Módulo II - Acabamento e Instalações Prediais, com a previsão de uma turma de 30 alunos.

\subsection{Torres de Santa Tereza (2004)}

No bairro de Santa Tereza, às margens da Avenida dos Andradas, em Belo Horizonte, destaca-se na paisagem duas torres de 17 andares. Após a falência da construtora e a paralisação das obras, os prédios, então apenas na alvenaria, foram, em 1997, ocupados por população de baixa renda (ver Artigos e Resumos sobre o tema). Eram 170 famílias, correspondendo a aproximadamente 550 pessoas, que então constituíram a Associação Comunitária dos Moradores do Residencial Saint Martin.

Após parcerias da Associação dos Moradores com a Pastoral de Rua (1988), a PUC Minas passou a participar do processo, inicialmente com o Serviço de Assistência Judiciária da PUC Minas - SAJ (1999), e em seguida com o EMAU - Escritório Modelo de Arquitetura e Urbanismo da PUC Minas (2002) e com o Escritório de Integração (2004).

Em um primeiro momento, foram articuladas providências de assessoria jurídica à comunidade, a fim de garantir sua per-
2. Arquiteto Alfredo Lanna, e a mestra de obras Cenir Aparecida da Silva. 
manência nos edifícios, enquanto se tramitava na Justiça um processo de compra dos edifícios pelos novos moradores, por meio do Programa Crédito Solidário.

O projeto propunha a autogestão em todas as etapas de seu processo, desde o assessoramento técnico à sociedade na organização e captação de recursos, até o desenvolvimento dos projetos e execução das obras. O El desenvolveu projetos de recuperação e operacionalização da capacidade instalada, de recuperação e requalificação ambiental e de desenvolvimento tecnológico da Construção Civil para minimização dos impactos ambientais negativos originados na atividade. Por fim, foram desenvolvidos os projetos arquitetônico e urbanístico, em cumprimento aos procedimentos necessários à análise de documentos pela Caixa Econômica Federal. Entretanto, o processo de financiamento na CEF não foi concretizado.

Além das já citadas parcerias, o projeto estabeleceu convênio com a SUDECAP - Superintendência de Desenvolvimento da Capital.

\subsection{Viadutos da Via Expressa (2004-2005)}

O projeto consta de um plano de requalificação e recuperação de áreas sob viadutos e passarelas da Via Expressa, em Belo Horizonte, no trecho compreendido entre o Complexo da Lagoinha (centro) e o Viaduto do bairro Camargos (região oeste).

Ele surgiu a partir de um envolvimento de famílias que moravam sob os viadutos com a Pastoral de Rua e o Serviço de Assistência Judiciária da PUC Minas - SAJ. O público atendido foi de 60 famílias, de moradores dos baixos de viadutos, catadores de materiais recicláveis, ambulantes, flanelinhas e moradores de rua dos bairros vizinhos. O projeto se viabilizou via Edital do Ministério das Cidades, em convênios e parcerias com a Pastoral de Rua, o SAJ da PUC Minas, Polos UFMG, Arquitetos Sem Fronteira, e a Prefeitura de Belo Horizonte, tendo se desdobrado em várias ações paralelas.

O projeto teve como objetivo viabilizar a incorporação efetiva à cidade formal destas áreas e de suas respectivas comunidades, que as ocuparam ao longo das últimas décadas. Para isso, o plano em questão adotou como base a elaboração de um diagnóstico multidisciplinar abrangendo os aspectos urbanísticos, ambientais, sociais, econômicos e jurídicos, que orientaram a definição das diretrizes de uso e ocupação.

Logo após o início do envolvimento do El com os moradores dos viadutos, foi desenvolvido o projeto de pesquisa Uso e apropriação de áreas urbanas residuais: perspectivas de reabilitação físico ambiental (ver Projetos de Pesquisa), que elaborou uma crítica histórica das áreas urbanas residuais, mais especificamente as contíguas aos viadutos.

A despeito do trabalho realizado, os moradores foram removidos dos viadutos, e após um processo jurídico, foi previsto reassentamento das famílias em terrenos próximos. No processo de reassentamento das famílias dos viadutos Silva Lobo e João Pinheiro, e da Passarela da Gameleira, o El ficou encarregado de projetar as novas habitações, em terreno ce- 
dido pela Prefeitura, que também financiaria a construção das moradias, baseada no conceito da autogestão. Paralelamente, foi realizado um projeto para ocupação das áreas em baixo de tais viadutos a fim de gerarem renda para esta população que foi dali retirada. O público atendido foi de nove famílias, com os mesmos convênios supracitados, e os projetos foram desenvolvidos em nível de Estudo Preliminar. Entretanto, ao final, a Prefeitura optou pela disponibilização de bolsa-aluguel às famílias desalojadas.

\subsection{O Programa Arquitetura e Engenharia Públicas (2005)}

O programa Arquitetura e Engenharia Públicas, promovido pela Prefeitura de Belo Horizonte e gerenciado pela URBEL Urbanizadora de Belo Horizonte, em parceria com a Secretaria de Habitação, atuava na assessoria de arquitetura e engenharia a populações de baixa renda. ${ }^{3}$ Ele busca suprir uma lacuna da assessoria técnica a moradias dessas populações, hoje não atendidas por estes serviços, seja pelo mercado formal da construção civil, seja pelos programas habitacionais geridos pelo poder público.

As moradias dessas populações desassistidas são tradicionalmente erguidas, na quase totalidade dos casos, no sistema de autoconstrução, que caracteriza a absoluta maioria da ocupação da chamada "cidade ilegal". O programa parte do princípio que a autoconstrução, se apoiada por uma adequada assessoria técnica, proporciona uma economia de recursos das famílias envolvidas, assim como uma melhor qualidade de vida urbana. Nessa assessoria, são levadas em consideração questões como: segurança edilícia, salubridade, durabilidade e racionalidade construtiva, dimensionamento e disposição dos cômodos e sua relação com o exterior, a privacidade e a promiscuidade, o conforto ambiental, a adequação espacial aos usos desejados e o respeito a formas de morar e conviver, a qualidade dos espaços coletivos e públicos e o desenvolvimento de uma imagem urbana diversa.

$\mathrm{O}$ trabalho privilegiou $\mathrm{O}$ atendimento às comunidades organizadas, alvo de programas mais amplos da $\mathrm{PBH}$. O El trabalhou em diversas vilas de Belo Horizonte, como Morro das Pedras, Aglomerado da Serra, Barreiro, Vila $1^{\circ}$ de Maio, Vila São José, Vila Engenho Nogueira e Minas Brasil.

Os projetos foram desenvolvidos buscando identificar e registrar os problemas específicos de cada situação e as soluções correspondentes. Buscou-se sempre a coletivização do conhecimento e a organização de dados e pesquisas, gerando condições de maior agilidade no atendimento e melhor capacitação dos agentes.

Os projetos, em um primeiro momento, buscaram aperfeiçoar o sistema construtivo disponibilizado pela URBEL, para em seguida introduzir alternativas técnico-construtivas consideradas mais eficazes. As soluções encontradas geraram um banco de dados passível de utilização em futuras intervenções, considerando a ampliação do atendimento baseada no conhecimento de um sistema de soluções (articuláveis, combináveis, inter-
3. O Programa foi extinto em 2006 
cambiáveis), mais eficaz e multiplicável que a reprodução de um padrão.

Dando visibilidade a uma prática projetual ética, comprometida com as necessidades da sociedade, o Programa buscou atrair o interesse dos jovens arquitetos para essa atuação, tendo como subproduto muito significativo a capacitação de profissionais conscientes e aptos a lidar com a realidade habitacional de assentamentos precários.

\subsection{Programa Crédito Solidário (2005-2007)}

O Programa Crédito Solidário foi desenvolvido através de uma parceria entre o Ministério das Cidades e a Prefeitura de Belo Horizonte, e posteriormente a outras prefeituras do Estado. Ele teve como objetivo projetar habitações para as populações de baixa renda organizadas pelas Associações dos Sem Casa da Grande BH. A PUC Minas ficou encarregada da assessoria técnica ao Programa, para o que contou com a participação de professores, alunos e ex-alunos do Curso de Arquitetura e Urbanismo.

Os projetos habitacionais foram desenvolvidos de acordo com as diretrizes e políticas de habitação do município: acesso a terra e à moradia digna; processos democráticos na formulação e implementação da política habitacional; processos tecnológicos que garantam qualidade e menor custo da habitação; formas de atuação que propiciem a geração de emprego e renda; vinculação da política habitacional com a política urbana. Além da elaboração de projetos arquitetônicos e urbanísticos, foram desenvolvidas e implementadas técnicas de grupo para promover a autogestão.

\section{Projetos realizados}

Para o Empreendimento Habitacional Mar Vermelho I (2005), foi desenvolvido o projeto arquitetônico e urbanístico. O público atendido foi de 105 famílias de baixa renda que moravam de aluguel, todas residentes em Belo Horizonte. O projeto estabeleceu convênios e parcerias com a União Estadual por Moradia (UEMP).

Para o Empreendimento Habitacional Santa Rosa II (2005), foi elaborado um projeto arquitetônico e urbanístico, assim como técnicas de grupo para promover a autogestão. O projeto foi elaborado também em convênio o com UEMP, e foram atendidas 50 famílias. A obra, já sem a participação da PUC, foi recentemente concluída.

O Empreendimento Habitacional Mar Vermelho II (20052007), chamado Residencial Serra Verde pelos moradores, foi financiado pelo FINEP (projetos e da assessoria técnica) e pela CEF (obra). Para este projeto, foi desenvolvida assessoria técnica habitacional em sistema de autogestão para concepção, execução, e gerenciamento de obras, e projetos de pesquisas em saneamento e arquitetura. O mutirão buscou inserir os futuros moradores em todas as etapas do processo, desde o projeto até a construção da edificação, adotando princípios da inclusão digital, da economia solidária e da sustentabilida- 
de socioeconômica. ${ }^{4} \mathrm{O}$ público atendido foi de 76 famílias de baixa renda da Associação dos Sem Casa - ASCA do Bairro Betânia e de outras regiões de Belo Horizonte. O Projeto ainda estabeleceu convênios e parcerias com a Escola de Arquitetura da UFMG, a URBEL (PBH), e a União Estadual por Moradia Popular (UEMP).

Em 2007, o El desenvolveu conjuntos habitacionais para associações de catadores de papel de vários municípios da Região Metropolitana de Belo Horizonte: ASCAP (Nova Lima), ASMAC (Contagem), Coopert (Itaúna) e APAIG (Igarapé). O Escritório de Integração entrou com a equipe de estagiários e professores orientadores, bem como suporte de para elaboração dos projetos arquitetônicos. Além de projetar novas moradias, se trabalhou também com a demanda de reformas de construções por parte dos associados, ambas financiadas pela Caixa Econômica Federal (CEF). Foi atendido um público de 44 famílias. O Projeto teve convênios e parcerias com as Associações de Catadores de Papel e Prefeituras Municipais. Foram desenvolvidos projetos arquitetônicos e urbanísticos.

Ainda em 2007, em contratos travados com a Prefeitura de Contagem, agenciados pela Pró-reitoria de Extensão da PUC Minas - PROGEF, foram elaborados projetos de conjuntos habitacionais para os bairros Sapucaia II, Mangueiras e Vila Itália.

\subsection{Espaços Urbanos Seguros: Programa Fica Vivo (2006-2007)}

O projeto Espaços Urbanos Seguros é uma proposta de adequação e aplicação da metodologia Crime Prevention Through Enviromental Design - CPTED ${ }^{5}$ no âmbito do programa Fica Vivo. Nele, trabalha-se a melhoria da qualidade dos espaços públicos em áreas urbanas, visando a segurança e prevenção ao crime. Ele foi realizado em convênio com a Secretaria de Estado de Defesa Social.

O projeto desenvolve empreendimentos de melhorias e da valorização dos espaços comuns, utilizando como instrumento o desenho urbano, em parceria com os moradores, promovendo a vigilância natural da comunidade local sobre seu meio ambiente com estratégias de reforço territorial, controle natural de acessos, manutenção ambiental e participação ativa da comunitária. Essa participação se deu no desenvolvimento do processo de autogestão em todas as fases do empreendimento: Projeto, produção, gestão, administração e fiscalização. Como objetivo secundário, o projeto visa a capacitação profissional para o desenvolvimento das atividades afeitas ao empreendimento, incluindo a administração dos recursos investidos e a captação de novos recursos para projetos futuros.

O trabalho foi desenvolvido, inicialmente, como um Projeto Piloto no Morro das Pedras, Belo Horizonte, para posteriormente ser estendido a outras áreas, onde atua o Programa Fica Vivo. ${ }^{6}$

\subsection{A Vila Novo Ouro Preto (2002-2012) ${ }^{7}$}

O projeto propôs uma série de intervenções na Vila, nos limites do bairro Ouro Preto, na região da Pampulha, em
4. Na etapa final do projeto, a equipe do El envolvida deu continuidade ao trabalho de maneira autônoma, sem vinculação com a PUC.
6. O projeto foi interrompido na fase de execução, em função de entraves burocráticos no repasse das verbas de execução para as associações de moradores.

7. Sobre o trabalho do El junto à Vila Novo Ouro Preto, ver artigos nesta edição: Análise e avaliação dos instrumentos jurídicos e urbanísticos para resgate da cidadania e aplicação da função social da propriedade - O caso da vila novo Ouro Preto; Vila Ouro Preto, a cidadania pelas águas, assessorando novas formas de autogestão; Mobilização socioambiental para novas formas de autogestão: O caso da Vila Novo Ouro Preto.

Cadernos de Arquitetura e Urbanismo, v.19, n.24+25, 2012 
Belo Horizonte. Ele teve convênio com a AMA Cidadania, e obteve recursos financeiros da Pró-Reitoria de Extensão da PUC Minas - PROEX.

O projeto visou, em especial, uma reurbanização integrada com instalação de redes de captação de esgoto sanitário e drenagem pluvial. Seu desenvolvimento englobou atividades como o levantamento de dados em campo, análise geológico-geotécnica, projetos de estabilização de encostas, planejamento de traçado viário, projetos de recuperação das áreas degradadas e de recuperação ambiental, e propostas de alternativas para o reassentamento das famílias envolvidas no processo.

\subsection{Na cidade sem meu carro (2004-2005)}

A jornada Na Cidade Sem Meu Carro surgiu como uma proposta de sensibilização para com a questão do automóvel nos centros urbanos e com a qualidade do ar das nossas cidades. No ano de 2000, a iniciativa surgiu em vários países da União Europeia, e em 2001 foi inaugurada em Belo Horizonte, sob a coordenação da ONG Rua Viva.

O El iniciou sua participação nas jornadas em 2004, projetando os espaços utilizados pela jornada. Em 2004, foi "construída" uma praça nos cruzamentos das ruas Rio de Janeiro e Goitacazes. O projeto recebeu, neste ano, o Prêmio Gentileza Urbana, promovido pelo IAB-MG. Em 2005, esta se entendeu até o cruzamento das ruas Rio de Janeiro com Tupis. E, a cada ano, aumenta o público que frequenta este espaço.

O projeto conta com a parceria da $\mathrm{PBH}$ e da BHTRANS viabilizando o fechamento das vias utilizadas para a jornada.

\subsection{Jardim de Petrópolis:(2004-2009)}

O trabalho do El com o bairro Jardins de Petrópolis, em Nova Lima - MG, se deu em dois momentos. O primeiro surgiu a partir de uma demanda da associação dos moradores locais para soluções alternativas para pavimentação das vias locais, com trechos de grande declividade e graves problemas de erosão. Em um segundo momento, trabalhou-se na recuperação da área da Cascalheira, área remanescente de mineração na encosta do Morro do Pires. Em ambos os casos, temos áreas afetadas por processos de degradação físico-ambientais, com erosões e voçorocas que atingem a mesoestrutura implantada e provocam o assoreamento de cursos d'água.

Foi montado um projeto de recuperação socioambiental das áreas, com uma cooperação tecnológico-cultural do Escritório de Integração com a Associação dos Moradores do Bairro Jardins de Petrópolis, em parceria com a Pró-Reitoria de Extensão da PUC Minas - PROEX. Como estratégia processual, buscou-se resgatar a cultura tecnológica local, para dela se valer no levantamento e solução dos problemas detectados. A partir da identificação desses problemas, foi elaborado um diagnóstico integrado sobre suas origens e manifestações, e soluções projetuais ambientalmente compatíveis e de baixo impacto, a serem implementadas pela Associação local, com mão de
8. Sobre o trabalho do El na área da Cascalheira, ver artigos nesta edição: Desequilíbrio ambiental, cultura local e cultura tecnológica; Recuperação socioambiental da área da Cascalheira. 
obra local devidamente capacitada para tal, em parceria com a Prefeitura Municipal.

No primeiro caso, foram apresentados projetos para um trecho piloto do sistema viário do bairro, que apresentava o leque mais amplo e significativo dos problemas detectados. No caso da Cascalheira, foram desenvolvidos projetos de requalificação e recuperação urbanístico/ambiental da área. Os projetos foram aprovados pela Associação, que passou a se articular para angariar verbas para sua implantação.

\subsection{Capacitação de agentes municipais em Regularização Fundiária (2010-2011)}

O projeto objetivou a capacitação técnica de agentes públicos municipais e representantes da sociedade civil de Pedro Leopoldo, qualificando-os para a implementação da regularização fundiária sustentável, como forma de concretizar o direito fundamental à moradia digna e, também, com vistas a criar condições para que os danos causados à ordem urbanística e ao meio ambiente em razão da ocupação informal e desordenada do espaço urbano fossem reparados.

O trabalho foi realizado com recursos financeiros da Agência de Desenvolvimento da Região Metropolitana de Belo Horizonte, e teve como produto a cartilha Regularização Fundiária, publicada nesta edição.

\subsection{Centro de Formação Popular - CEFOP (2011-2013)}

O projeto do CEFOP é um desdobramento de ações anteriores do El junto à Via Campesina ${ }^{9}$. Em um primeiro momento, foi demandado um projeto para a Escola de Formação de Trabalhadores e Trabalhadoras Rurais e Museu da Luta pela Terra em Minas Gerais, como instância primeira de um processo para obtenção de recursos para realização da obra. O projeto se iniciou em 2010, desenvolvido na disciplina Projeto de Edifício de Grandes Vãos (ver item Laboratórios), e em 2011 foi financiado pela Pró-Reitoria de Extensão da PUC Minas - PROEX, contando com a participação de professores dos cursos de Arquitetura e Urbanismo e de Ciências Sociais da PUC Minas. Com a aquisição de um terreno maior, em Ribeirão das Neves, na Região Metropolitana de Belo Horizonte, partiu-se, em 2012, para um novo projeto, o do Centro de Formação Popular - CEFOP.

O projeto da Escola, elaborado de modo participativo, englobou desde o estudo preliminar ao projeto legal, incluindo a assessoria técnica para captação de recursos e para a construção, e cursos de formação de mão de obra. O sistema participativo de projeto já amadurecido na relação entre o $\mathrm{El}$ e as diversas instituições com compõem o CEFOP, propiciou uma maior clareza na definição tanto do programa arquitetônico quanto do processo de produção dos projetos e de construção, a se darem em regime de autoprodução.

Como primeiro produto, foi elaborado o projeto arquitetônico da Casa da Administração, o primeiro dos projetos a serem construídos. Para continuidade ao projeto, atualmente finan-
9. A Via Campesina é um espaço de articulação e mobilização de movimentos sociais camponeses e entidades de apoio à luta dos trabalhadores e trabalhadoras que vivem no campo. Atuando desde o âmbito local ao internacional, ela protagoniza espaços de diálogo na esfera pública, apresentando demandas e pressionando práticas que promovam a construção de políticas públicas que possibilitem a inclusão social, o fim da violência, a partilha de riquezas e a preservação do espaço natural de reprodução das comunidades tradicionais. 
ciado pela Pró-Reitoria de Extensão da PUC Minas - PROEX, programa-se articulá-lo a outras iniciativas de extensão do Instituto de Ciências Sociais da PUC Minas - ICS, especialmente ao projeto Construção e Cidadania e ao projeto Lições da Terra.

Ao longo do seu desenvolvimento, o projeto do CEFOP estabeleceu parcerias com diversas instituições: Consulta Popular, Assembleia Popular, MAB - Movimento dos Atingidos por Barragens, MPA - Movimento dos Pequenos Agricultores, FEAB - Federação dos Estudantes de Agronomia do Brasil, MST - Movimento dos Trabalhadores Rurais sem Terra, CPT Comissão Pastoral da Terra, PJR - Pastoral da Juventude Rural, MMC - Movimento de Mulheres Camponesas, MMM - Marcha Mundial de Mulheres, CIMI - Conselho Indigenista Missionário, Sindicatos dos Trabalhadores dos Leste de Minas Gerais, MTD - Movimento dos Trabalhadores Desempregados, Juventude do PDT, e Caritas.

\section{PROJETOS DE PESQUISA}

\subsection{Mutirão São Gabriel (2001-2004)}

O Mutirão São Gabriel se originou como um projeto de pesquisa da Escola de Arquitetura da UFMG, em parceria com o Escritório de Integração, financiado pelo FINEP.

O projeto Mutirão São Gabriel: Tecnologias Avançadas de Informática para Novas Formas de Autogestão foi um projeto de pesquisa financiado pelo FINEP, coordenado pela Profa. Maria Lucia Malard, da Escola de Arquitetura da UFMG, em parceria com o Escritório de Integração da PUC Minas. O projeto trabalhou no desenvolvimento de procedimentos metodológicos informatizados e participativos, disponibilizáveis via internet, para o aperfeiçoamento da concepção e gestão da produção de moradias em sistema de mutirão.

Uma vez entregue o produto final, o Escritório de Integração recebeu um convite da FINEP para desenvolver o projeto do Empreendimento Habitacional Mar Vermelho II (RSV), constante de assessoria técnica habitacional em sistema de autogestão para concepção, execução, e gerenciamento de obras, e projetos de pesquisas em saneamento e arquitetura, com verba para execução da CEF via Programa de Crédito Solidário.

\subsection{Uso e apropriação de áreas urbanas residuais: perspectivas de reabilitação físico ambiental (2004-2005)}

A pesquisa, desenvolvida sob a coordenação da Professora Alícia Pena, do Departamento de Arquitetura e Urbanismo, foi financiada pelo Fundo de Incentivo à Pesquisa - FIP, da PUC Minas. A pesquisa fez uma crítica histórica das áreas urbanas residuais áreas, mais especificamente as contíguas aos viadutos, discutindo o porquê estas áreas subutilizadas não poderem ficar ociosas. O principal produto direto deste projeto foi o Diário de Obras No 1: Boletim do Escritório de Integração - O assunto é: viadutos urbanos, agora publicado neste número dos Cadernos. 
A pesquisa foi desenvolvida em paralelo ao projeto de extensão Plano de Requalificação e Recuperação dos Viadutos da Via Expressa, desenvolvido pelo El, em pareceria com outras entidades (ver Projetos de Extensão).

\subsection{Alternativas Tecnológicas para Elementos de Mesoestrutura Urbana para Assentamentos informais (2006-2007)}

O projeto, desenvolvido sob a coordenação do professor Rogério Palhares Zschaber de Araujo, do Departamento de Arquitetura e Urbanismo, foi financiado pelo Fundo de Incentivo à Pesquisa - FIP, da PUC Minas. A pesquisa foi motivada pela hipótese de que os padrões praticados na cidade formal não se adaptam à realidade específica da urbanização dos assentamentos informais, caracterizados pela ocupação de áreas ambientalmente frágeis, pela exiguidade de espaço, pela dificuldade de acesso e por maiores restrições orçamentárias. A pesquisa resultou em um banco de dados digital contendo 67 técnicas e dispositivos não convencionais, classificados segundo sua aplicação, desempenho, sistema construtivo e custo.

Várias das soluções desenvolvidas nessa pesquisa foram aplicadas no projeto de recuperação ambiental do Jardins de Petrópolis, desenvolvido pelo El (ver Projetos de Extensão), sobretudo soluções de drenagem e pavimentação.

\subsection{A difusão da tecnologia Estrutural no Brasil (2010-2011)}

A pesquisa, desenvolvida pelo Prof. Roberto Eustaáquio, do Departamento de Arquitetura e Urbanismo, foi financiada pelo Fundo de Incentivo à Pesquisa - FIP, da PUC Minas. O objetivo foi investigar a difusão da tecnologia da alvenaria estrutural, a partir das publicações levantadas durante a pesquisa Laboratório de Pesquisa em Projeto de Alvenaria Estrutural (ver item Laboratórios). Foi feita uma leitura crítica dessas publicações, um mapeamento dos centros de pesquisa e dos pesquisadores que desenvolveram e/ou desenvolviam pesquisa na área da Alvenaria Estrutural, de maneira a aferir o grau de difusão desta tecnologia.

\subsection{Metodologias para concepção \\ e gestão participativas de intervenções em Meio Urbano - Assessoria Técnica à Autogestão (2010-2013)}

O projeto, coordenado pela profa. Rita Liberato, da PUC Minas, e financiado pela FAPEMIG, é a mais recente ação decorrente do envolvimento do Escritório de Integração com a comunidade da Vila Ouro Preto (ver item Projetos de Extensão). Ele busca desenvolver, em conjunto com os moradores locais, metodologias de projeto e planejamento participativos de autogestão, visando capacitá-los, através do desenvolvimento de suas habilidades e competências, a planejar, elaborar, captar recursos, gerenciar, fiscalizar e participar ativamente da construção de um protótipo para o Residencial da Cidadania e, por fim, avaliá-lo. 


\section{LABORATÓRIOS DE ENSINO, PESQUISA E EXTENSÃO}

Os Laboratórios de Extensão e Pesquisa, previstos no Projeto Pedagógico do Curso de Arquitetura e Urbanismo da PUC Minas, se configuram como alternativas pedagógicas de disciplinas do Ciclo Profissionalizante $1\left(4^{\circ}, 5^{\circ}\right.$ e $6^{\circ}$ períodos $)$ do Curso de Arquitetura e Urbanismo da PUC Minas. Eles possibilitam a interação entre conteúdos disciplinares e projetos de extensão e pesquisa, associados às atividades e linhas de atuação do El. As atividades de ensino no sistema de Laboratório são optativas por parte do professor responsável pela disciplina, e demandam um esforço de experimentação e de sistematização dessas novas práticas pedagógicas.

\subsection{Canteiro em Obras (desde 2009)}

O projeto Canteiro em Obras consiste em atividades práticas de construção, oferecidas a todos os alunos do Curso de Arquitetura e Urbanismo da PUC Minas. Elas se realizam aos sábados, duas vezes por semestre, e fazem parte do calendário escolar do curso.

Algumas das disciplinas do Ciclo Profissionalizante I do Curso articulam seus programas com as atividades do Canteiro, permitindo assim a vivência da execução de tecnologias construtivas ensinadas.

\subsection{Projeto de Alvenaria Estrutural:}

\section{Laboratório de ensino e pesquisa (2010) ${ }^{10}$}

O projeto, realizado no âmbito da disciplina Projeto de Alvenaria Estrutural, teve como objeto a investigação do referido sistema. Foi criado um ambiente de ensino-aprendizagem voltado para a reflexão acerca da prática a partir da própria prática, uma prática refletida que considere não somente os aspectos imediatos do projeto e da obra civil, mas também os demais agentes e fatores da cadeia produtiva da do espaço construído, especialmente no que se refere à formação de mão de obra para a construção civil.

\subsection{Projeto de Estruturas de Madeira e Aço:} Associação Comunitária do Bairro Gameleira e Adjacểncias (2010)"11

O projeto trabalhou no projeto da sede da Associação Comunitária do Bairro Nova Gameleira e Adjacências, com espaço administrativo e ambiente para encontros comunitários, cursos profissionalizantes e palestras. O projeto teve como parceira a Associação local e recursos da Pró-Reitoria de Extensão da PUC Minas - PROEX.

\subsection{Projeto de Edifício de Grandes Vãos:}

Escola Estadual de Formação de Trabalhadores e Trabalhadoras Rurais e Museu da Reforma Agrária em Minas Gerais (2010) ${ }^{12}$

O projeto surgiu a partir de uma demanda da Via Campesina. Tratava-se de um espaço onde os agricultores familiares do
10. O projeto foi coordenado pelo Prof. Roberto Eustaáquio dos Santos.

11. Projeto coordenado pela profa. Hilda Cotegipe Pellico.
12. Projeto coordenado pela profa. Hilda Cotegipe Pellico.

Cadernos de Arquitetura e Urbanismo, v.19, n.24+25, 2012 
Estado possam socializar as informações e se apropriarem das experiências de educação e de formação. Neste laboratório, explorou-se a cobertura como elemento de articulação entre o ensino e a extensão, entre o conteúdo disciplinar e a demanda real de solução de projeto da comunidade em questão.

\subsection{Projeto de Alvenaria Estrutural: habitações do conjunto Dandara (2011), e alojamento do CEFOP (2012) ${ }^{13}$}

Nesta disciplina, foram feitos projetos habitacionais para a ocupação Dandara, e um projeto para o alojamento do Centro de Formação Popular - CEFOP. Em ambos os projetos, valeu-se da alvenaria estrutural como sistema construtivo capaz de articular o ensino, o projeto real e a capacitação de mão de obra.

4.6. Projeto de Racionalização Construtiva: Associação de Pais e Amigos de Excepcionais - APAE, em Conceição do Mato Dentro - MG (2012)

O projeto visou atender uma demanda da Associação de Pais Amigos dos Excepcionais - APAE, de Conceição do Mato Dentro. Trata-se de um projeto arquitetônico no qual se privilegia a pesquisa e o produto no aspecto da racionalização construtiva. O projeto visa também capacitar a Associação para captar parcerias que possam viabilizar a execução da obra.
13. Os Laboratórios foram desenvolvidos pelas professoras Margarete Maria de Araújo Silva (Leta), Priscila Nogueira e Tatiana Soledade Delfanti Melo. 